\title{
MiR-221, a potential prognostic biomarker for recurrence in papillary thyroid cancer
}

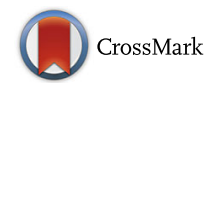

\author{
Lei Dai, Yaozong Wang, Liangliang Chen, Jueru Zheng, Jianjun Li and Xianjiang Wu
}

\begin{abstract}
Background: Many studies have reported several transcriptionally deregulated microRNAs (miRNAs) in papillary thyroid cancer (PTC) tissue in comparison with benign thyroid nodules and normal thyroid tissues. However, the correlation between miRNA expressions and PTC recurrence still remains unclear.

Methods: The PTC patients who scheduled to undergo total thyroidectomy by the same surgical team in Ningbo NO.2 Hospital from March 1998 to March 2008 were enrolled in this study. The clinical and pathological characteristics of each patient were recorded in detail. The selected miRNA expressions were detected using quantitative reverse transcriptase-polymerase chain reaction (qRT-PCR). Potential predictive factors for cancer recurrence were evaluated by univariate and multivariate Cox proportional hazard analysis.
\end{abstract}

Results: A total of 78 patients were enrolled with 49 females at a mean age of 45.8 years. Enrolled patients were divided into two groups: nonrecurrent group $(n=54)$ and recurrent group $(n=24)$. The results from the univariate Cox proportional hazard analysis revealed that primary tumor size, TNM stage, extrathyroid extension, miR-221, and miR-222 expressions were significantly associated with PTC recurrence $(P<0.05)$. The tissue expression of miR-221 was the only independent risk factor for PTC recurrence (HR 1.41; 95\% CI 1.14-1.95, $P=0.007)$ by multiple Cox proportional hazard analysis.

Conclusions: This study identified the potential role of miR-221 as a prognostic biomarker for the recurrence in PTC.

Keywords: Papillary thyroid cancer, Recurrence, Biomarker, miR-221

\section{Background}

Thyroid cancer is the most prevalent and rapidly increasing endocrine neoplasm. The number of new cases is almost 300,000 worldwide with a median age at diagnosis of 50 years and nearly 40,000 deaths per year [1]. The most common histological type of all thyroid cancers is papillary thyroid cancer (PTC), which is defined as a differentiated neoplasia and accounts for approximately $80 \%$. Most PTC patients are with good prognosis, and the 10-year survival rate is about $90 \%$ [2]. However, the incidence of lymph node metastasis can be as high as $20-50 \%$ [3], and PTC patients undergoing total thyroidectomy are with a regional recurrence of $5-20 \%[4,5]$. Currently, needle aspiration biopsy is the gold standard for diagnosis, but the predicative value for recurrence is rather limited [6]. Risk factors

\footnotetext{
* Correspondence: wuxianjiangtg@163.com

Department of Thyroid Surgery, Ningbo NO.2 Hospital, NO.41 Xibei Street,

Ningbo City 315000, Zhejiang Province, China
}

for the prognosis and recurrence of PTC are controversial among different current guidelines $[7,8]$. Therefore, investigating potential useful markers for the identification and distinction of recurrence risk factors is extremely imperative and necessary [9].

MicroRNAs (miRNAs), small noncoding single-stranded RNAs, exert important actions in the development and metastasis of cancer as reported by previous studies $[10,11]$. Some miRNAs have already been suggested as potential prognostic markers for the evaluation of cancer types, stages, or progression [12, 13]. Recent studies have also observed several transcriptionally deregulated miRNAs in PTC tissue in comparison with benign thyroid nodules and normal thyroid tissues $[14,15]$. However, the correlation between miRNA expressions and PTC recurrence still remains unclear.

Previous studies have frequently reported that some miRNAs including miR-21, miR-9, miR-10b, miR-146b, miR-31, miR-220, miR-221, and miR-222 are abnormally 
expressed in thyroid cancers compared with healthy controls [16-19]. In this present study, we investigate the potential role of these miRNAs in the recurrence of PTC.

\section{Methods}

\section{Patients}

This study protocol was approved by the Medical Institutional Ethics Committee of Zhejiang province. The PTC patients who scheduled to undergo total thyroidectomy by the same surgical team in Ningbo NO.2 Hospital from March 1998 to March 2008 were eligible to enter this study. All patients included were required to offer written informed consent. The formalin-fixed, paraffin-embedded (FFPE) PTC tissues were procured for the postoperative histopathologic diagnosis and miRNA measurements. Those patients with poor quality of tissues, missed follow-up data, or with no signed informed consent were excluded from this study. A total of 78 patients were enrolled with 49 females $(62.8 \%)$ at a mean age of 45.8 years. Enrolled patients were divided into two groups: nonrecurrent group $(n=54)$ and recurrent group $(n=24)$. Only those patients with no recurrence after a 120-month follow-up evaluated by clinical, laboratorial, and radiological evidence were categorized in nonrecurrent group. Recurrence in this present study was defined as locoregional recurrence or distant metastasis. The median follow-up period was 68 (range $8-158$ ) months.

\section{Methods}

Selective neck dissections were performed in PTC patients with regional lymph node metastases considering the metastases location. Our practice including the radioactive iodine (RAI) and surgical management evolved according to the latest American Thyroid Association (ATA) guidelines. All the patients were followed up through outpatient department clinic regularly over time. The conduction of postoperative RAI therapy was under the direction of the ATA guidelines [7]. Two independent pathologists blinded to this study were required for the evaluation of tumor histopathologic features. The ATA classification, risk stratification by Memorial Sloan Kettering Cancer Center (MSKCC-NY) [20], and stage by Union for International Cancer Control (UICC) TNM [21] were also evaluated. The clinical and pathological characteristics of each patient were recorded in detail.

\section{Tissue samples and RNA extraction}

In this study, we use the areas containing over $>90 \%$ malignant tissue annotated by the same experienced pathologist as the available PTC tissue samples. Manual macrodissection was performed in archival FFPE blocks for RNA extraction. Approximately 5-10-umthick sections from the FFPE PTC tissues were obtained for total RNA extraction by utilizing RNeasy Kit (Qiagen, Hilden, Germany) according to the manufacturer's instructions. NanoDrop ND1000 Spectrophotometer (ThermoFisher Scientific, Waltham, Mass) was used for the assessment of RNA quality and concentration.

\section{qRT-PCR for miRNA measurement}

The miRNA expressions were detected using quantitative reverse transcriptase-polymerase chain reaction (qRT-PCR) with TaqMan miRNA assays (Applied Biosystems, Foster City, Calif) and the $\Delta \Delta \mathrm{Ct}$ method. In brief, TaqMan miRNA primers were used for the synthesis of cDNA from total RNA, following the manufacturer's instructions. The TaqMan miRNA probes and a 7500 Real-time PCR System were utilized for amplification of PCR products. Two PCR reactions were performed per sample following the manufacturer's protocol. RNU48 expression levels were used as an endogenous control for data normalization [22]. As for those cases of multifocal PTCs, the sample obtained from available multifocal PTC tissues was all subjected to miRNA qRT-PCR. The final data were described with the mean value.

\section{Statistical analysis}

SPSS 21.0 (SPSS, Inc.) was utilized for data analysis in this study. Data were presented as number $(n)$ and percentage (\%), or mean \pm standard error (SE) when appropriate. We used chi-square or Fisher's exact tests to analyze clinical categorical data as appropriate. Continuous data was analyzed by Student's $t$ tests or Mann-Whitney $U$ tests. Potential predictive factors for cancer recurrence were evaluated by univariate and multivariate Cox proportional hazard analysis, and statistical difference was set as $P<0.05$.

\section{Results}

\section{Patient characteristics and PTC recurrence}

A total of 78 eligible patients with a mean age of 45.8 years and mean tumor size of 24.5 (range 8-47) $\mathrm{mm}$ were enrolled in this study with signed informed consent. Fifty-four of all the included patients were categorized into nonrecurrent group with a mean age of 44.9 years.

It has been observed that those patients with higher ATA risks, higher MSKCC-NY risks, a larger primary tumor size, or higher TNM stages were more likely to result in the PTC recurrence $(P<0.05)$ (see Table 1 ). Moreover, the patients in recurrent group were also with a higher percentage of extrathyroid extension and cervical lymph node metastasis $(P<0.05)$. 
Table 1 Characteristics of patients and PTC recurrence

\begin{tabular}{|c|c|c|c|}
\hline Parameters & $\begin{array}{l}\text { Recurrent } \\
\text { group }(n=24)\end{array}$ & $\begin{array}{l}\text { Nonrecurrent } \\
\text { group }(n=54)\end{array}$ & $P$ value \\
\hline Age (year) & $44.9 \pm 22.5$ & $46.2 \pm 18.9$ & 0.792 \\
\hline \multicolumn{4}{|l|}{ Sex } \\
\hline Male & $5(\%)$ & $13(\%)$ & 0.754 \\
\hline Female & $19(\%)$ & $41(\%)$ & \\
\hline \multicolumn{4}{|l|}{ ASA physical status } \\
\hline । & $8(\%)$ & $20(\%)$ & 0.673 \\
\hline$\|$ & $11(\%)$ & $27(\%)$ & \\
\hline III & $5(\%)$ & $7(\%)$ & \\
\hline BMI $\left(\mathrm{kg} / \mathrm{m}^{2}\right)$ & $21.4 \pm 4.3$ & $20.7 \pm 3.8$ & 0.473 \\
\hline \multicolumn{4}{|l|}{ ATA risk } \\
\hline Low & 6 & 28 & $0.030^{*}$ \\
\hline Intermediate & 14 & 24 & \\
\hline High & 4 & 2 & \\
\hline \multicolumn{4}{|l|}{ MSKCC-NY risk } \\
\hline Low & 4 & 11 & $0.017^{*}$ \\
\hline Intermediate & 10 & 36 & \\
\hline High & 10 & 7 & \\
\hline Primary tumor size (mm) & $29.4 \pm 5.4$ & $22.3 \pm 4.8$ & $<0.001^{*}$ \\
\hline Lymph node dissection & $15(62.5 \%)$ & $37(68.5 \%)$ & 0.603 \\
\hline RAI postoperatively & $6(25.0 \%)$ & $22(40.7 \%)$ & 0.181 \\
\hline \multicolumn{4}{|l|}{ Recurrence place } \\
\hline Locoregional & $22(\%)$ & $47(\%)$ & \\
\hline Distant metastasis & $2(\%)$ & $7(\%)$ & 0.713 \\
\hline Serum thyroglobulin (ng/mL) & $1.6 \pm 1.4$ & $1.0 \pm 1.3$ & 0.071 \\
\hline \multicolumn{4}{|l|}{ TNM stage } \\
\hline $\mid-\|$ & 13 & 43 & $0.021^{*}$ \\
\hline III-IV & 11 & 11 & \\
\hline
\end{tabular}

Extrathyroid extension

Yes

Vascular invasion

Yes

No

Perineural invasion

$$
\text { Yes }
$$

No

Cervical lymph node metastasis

$$
\text { Yes }
$$$$
\text { No }
$$

Histological subtype

$$
\text { Classic }
$$

Follicular

\begin{tabular}{|c|c|c|c|}
\hline \multicolumn{4}{|c|}{ Multifocal tumors } \\
\hline Yes & 13 & 19 & \multirow[t]{2}{*}{0.116} \\
\hline No & 11 & 35 & \\
\hline \multicolumn{4}{|c|}{ Bilateral tumors } \\
\hline Yes & 7 & 16 & \multirow[t]{2}{*}{0.967} \\
\hline No & 17 & 38 & \\
\hline
\end{tabular}

Table 1 Characteristics of patients and PTC recurrence (Continued)

\section{Tissue miRNA expressions and PTC recurrence}

To investigate the potential associations between tissue miRNA expressions and PTC recurrence, we evaluated miR-21, miR-9, miR-10b, miR-146b, miR-31, miR-220, miR-221, and miR-222 by qRT-PCR. As shown in Table 2, miR-146b, miR-220, miR-221, and miR-222 were markedly higher, while miR-9 and miR-21 expressions were significantly lower in recurrent group when compared with the nonrecurrent group $(P<0.05)$.

\section{Univariate and multiple Cox proportional hazard analysis for PTC recurrence}

The univariate and multiple Cox proportional hazard analysis was utilized for the investigation of potential variables for predicating PTC recurrence. The all potential recurrence-associated variables including clinical, pathological parameters, and tissue miRNA expressions (Table 1 and Fig. 1) were involved into Cox proportional hazard model. The results from univariate Cox proportional hazard analysis revealed that primary tumor size, TNM stage, extrathyroid extension, miR-221, and miR222 expressions were significantly associated PTC recurrence $(P<0.05)$. The tissue expression of miR-221 was the only independent risk factor for PTC recurrence (HR 1.41 ; 95\%CI $1.14-1.95, P=0.007$ ) by multiple Cox proportional hazard analysis (Table 3 ).

\section{MiR-221 and other recurrence-associated parameters}

No close association between miR-221 levels and time to recurrence was found by linear analysis. As shown in Table 3, the patients with higher miR-221 expressions (>median level) were associated with higher thyroglobulin levels. There was no significant association between miR-221 levels with disease-free interval and cervical lymph node metastasis rate.

\section{Discussion}

The valid predicative biomarkers for PTC recurrence would help adequate assessment of PTC patients, less 
Table 2 Univariate and multiple Cox proportional hazard analysis between clinical and pathological variables with PTC recurrence

\begin{tabular}{|c|c|c|c|c|}
\hline \multirow[b]{2}{*}{ Variables } & \multicolumn{2}{|l|}{ Univariate } & \multicolumn{2}{|l|}{ Multivariate } \\
\hline & $\mathrm{HR}(95 \% \mathrm{Cl})$ & $P$ value & $\mathrm{HR}(95 \% \mathrm{Cl})$ & $P$ value \\
\hline \multicolumn{5}{|l|}{ ATA risk } \\
\hline Low $\times$ high & $1.67(0.38-7.64)$ & 0.389 & & \\
\hline Low $\times$ intermediate & $0.87(0.29-3.35)$ & 0.879 & & \\
\hline Intermediate $\times$ high & $3.34(1.42-6.75)$ & 0.087 & & \\
\hline \multicolumn{5}{|l|}{ MSKCC-NY risk } \\
\hline Low $\times$ high & $1.67(0.77-3.98)$ & 0.196 & & \\
\hline Low $\times$ intermediate & $2.12(0.78-5.86)$ & 0.132 & & \\
\hline Intermediate $\times$ high & $1.45(0.52-3.88)$ & 0.243 & & \\
\hline Primary tumor size & $5.14(3.14-11.64)$ & $0.009^{*}$ & $1.54(0.43-7.67)$ & 0.567 \\
\hline \multicolumn{5}{|l|}{ TNM stage } \\
\hline$|/||\times||| / \mid V$ & $4.31(2.01-9.87)$ & $0.011^{*}$ & $2.68(1.10-6.72)$ & 0.067 \\
\hline Extrathyroid extension & $2.12(0.78-6.81)$ & $0.021^{*}$ & $2.53(0.54-12.42)$ & 0.314 \\
\hline Cervical lymph node metastasis & $2.85(0.76-6.12)$ & 0.107 & & \\
\hline $\operatorname{miR}-21$ & $2.01(0.33-5.43)$ & 0.132 & & \\
\hline miR-9 & $1.32(0.54-4.53)$ & 0.225 & & \\
\hline miR-146b & $1.11(0.24-4.13)$ & 0.682 & & \\
\hline miR-220 & $1.13(0.45-4.14)$ & 0.745 & & \\
\hline miR-221 & $1.46(1.20-1.88)$ & $0.001^{*}$ & $1.41(1.14-1.95)$ & $0.007^{*}$ \\
\hline miR-222 & $2.81(1.11-7.21)$ & $0.021^{*}$ & $1.86(0.76-5.65)$ & 0.226 \\
\hline
\end{tabular}

PTC, papillary thyroid cancer, ATA American Thyroid Association, MSKCC-NY Memorial Sloan Kettering Cancer Center, Cl confidence interval, $H R$ hazard ratio

${ }^{*} P$ value $<0.05$

prophylactic lymph node resections, or extensive surgeries. Whether prophylactic cervical lymph node dissection could improve postoperative survival or prevent PTC recurrence still remains controversial [23, 24]. However, no such effective biomarkers have been found until now, and great efforts are carried out by researchers for this purpose. This present study aimed at investigating potential biomarkers for PTC recurrence including tissue miRNA expressions.

Previous studies have revealed that larger tumor size was associated with increased incidence of nodal spread and worse prognosis $[25,26]$. Several reports have also suggested tumor size as a predictor for central lymph node metastases in PTC patients [27]. However, our final
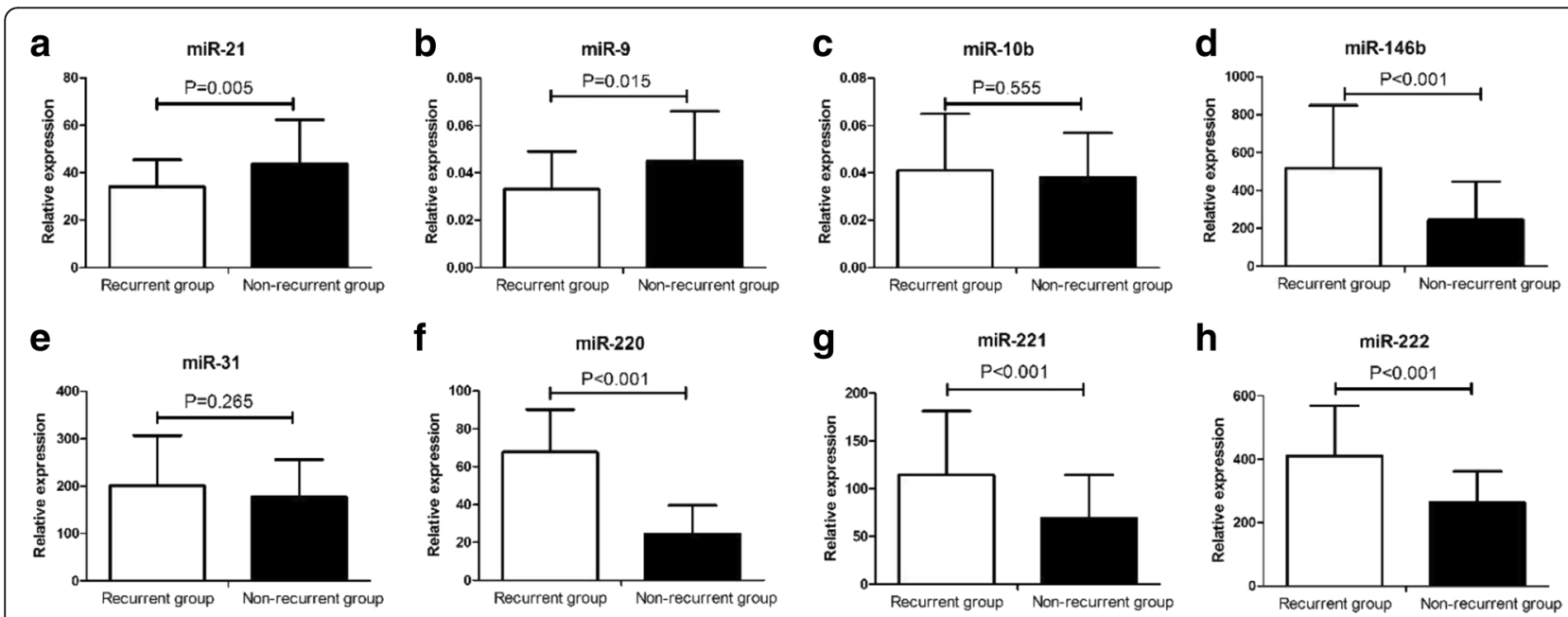

Fig. 1 Relative expressions of tissue microRNAs including miR-21 (a), miR-9 (b), miR-10b (c), miR-146b (d), miR-31 (e), miR-220 (f), miR-221 (g) and miR-222 (h) in papillary thyroid cancer (PTC) patients with or without recurrence 
Table 3 Relative miR-221 expressions and recurrence-associated parameters

\begin{tabular}{llll}
\hline & \multicolumn{3}{l}{ Relative expressions of miR-221 } \\
\cline { 2 - 4 } Parameters & High $(n=12)$ & Low $(n=12)$ & $P$ value \\
\hline Disease-free interval (year) & $1.8 \pm 4.7$ & $1.3 \pm 5.3$ & 0.801 \\
Thyroglobulin $(\mathrm{ng} / \mathrm{mL})$ & $1.5 \pm 1.0$ & $0.6 \pm 0.9$ & $0.031^{*}$ \\
Cervical lymph node metastasis & $5 / 12$ & $2 / 12$ & 0.371
\end{tabular}

$P$ values were calculated by Mann-Whitney $U$ tests or Fisher's exact test ${ }^{*} P$ value $<0.05$

multiple Cox analysis did not support these factors as predictive factors for PTC recurrence.

Previous studies have revealed the oncogenic and tumor suppressor roles of miRNAs during the formation and progression of tumors through the pathway modulation. Furthermore, several miRNAs have been reported closely correlated with the proliferation, progression, metastasis, and invasion of tumors [12]. Some researchers also suggest some miRNAs may exert predictive roles in cancer [13]. However, whether tissue or serum miRNAs could actually assist in the predication of PTC recurrence is still unclear. In this study, we examined a panel of tissue miRNA expressions to investigate potential biomarkers for PTC recurrence by qRTPCR. The tissue expressions of miR-9, miR-21, miR-146b, miR-220, miR-221, and miR-222 in recurrent group were significantly different from the nonrecurrent group. The downregulated miR-9 and miR-21 expressions in recurrent group comparing with nonrecurrent group were in accordance with other studies [1]. MiR-146b is also reported overexpressed in PTC tissues and closely associated with high-risk features including BRAF mutation or extrathyroidal invasion [28]. Overexpressed miR-221 and miR-222 in PTC are closely correlated with clinicpathological characteristics and tumor aggression $[15,19]$. As reported by previous studies, miR-220 was deregulated in the PTC tissues vs. the normal tissues [14]. Our analysis demonstrated that miR-220 expressions were significantly higher in recurrent group compared with nonrecurrent group. In this present study, we indicated miR-221 expressions in PTC samples as potential biomarkers for PTC recurrence. Excessively secreted miR-221 levels have been observed in PTC, follicular, and anaplastic thyroid cancers [29]. Previous studies also indicate that excessive expressions of miR-221 act as an important role in the proliferation of thyroid cancer cells [14]. Sehu S et al. also report the significantly different expressions of miR-221 between benign follicular adenoma, multinodular goiter, and PTC samples [30]. All these findings strongly suggest a close correlation between miR-221 and PTC.

Some findings have revealed the crucial role of miR-221 in the occurrence or progression of human osteosarcoma and suggested miR-221 as a promising marker for the diagnostic and prognostic potentials for osteosarcoma
[31]. MiR-221 was also recommended as a significant prognostic factor of clear cell renal cell carcinoma [32]. As one of the most sensitive miRNAs for PTC [33], miR-221 was identified as a predictive biomarker for PTC recurrence in this study. Enhanced expression of miR-221 and miR-222 plays a critical role in melanoma progression by activating fundamental pathways, such as blocking melanogenesis and inducing cell survival [34]. F. Acibucu et al. indicate that upregulated miR-221 can promote breast cancer progression by suppressing E-cadherin expression [35]. MiR-221 is established as a tumor suppressor for prostate cancer uniquely by targeting Runx2 [36]. These may be possible molecular mechanisms of that miR-221 lead to increased cancer growth and progression.

\section{Conclusions}

In conclusion, this study identified miR-221 as a significant independent predictor for PTC recurrence. However, our study also had some limitations. First, a long-term follow-up in the current study and larger cohorts are required to support miR-221 as a useful biomarker for PTC recurrence in clinical practice. Second, the ATA guidelines changed throughout the collection period, and our practice including the RAI and surgical management evolved according to the latest ATA guidelines. Whether the changed RAI and surgical management would affect our results remained unclear. Third, the involved mechanisms why miR-221 expression could serve as potential predicative factor for recurrence in PTC still remained unknown.

\section{Abbreviations}

ASA: American Society of Anesthesiologists; ATA: American Thyroid Association; BMI: Body mass index; Cl: Confidence interval; FFPE: Formalin-fixed, paraffin-embedded; HR: Hazard ratio; MSKCC-NY: Memorial Sloan Kettering Cancer Center; PTC: Papillary thyroid cancer; qRT-PCR: Quantitative reverse transcriptase-polymerase chain reaction; RAl: Radioactive iodine

\section{Acknowledgements}

Not applicable.

\section{Funding}

This study was supported by the Natural Science Foundation of Ningbo (No. 2015A610227) and The Subject of Regional Center for Tumor Diseases in

Zhejiang Province (No. 2014-98). The fundings played no roles in the design of the study and collection, analysis, and interpretation of data and in writing the manuscript. We declared that there were no financial conflicts.

\section{Availability of data and materials}

Please contact author for data requests.

\section{Authors' contributions}

LD, YZW, LLC, and JRZ participated in the conception and design, data collection, and statistical analysis and wrote the manuscript. JJL and XJW participated in the conception and design and data collection. All authors read and approved the final manuscript.

Competing interests

The authors declare that they have no competing interests.

Consent for publication

Not applicable. 


\section{Ethics approval and consent to participate}

This study protocol was approved by the Medical Institutional Ethics Committee of Zhejiang province. All patients included were required to offer written informed consent.

Received: 1 September 2016 Accepted: 22 December 2016

Published online: 07 January 2017

\section{References}

1. Sondermann A, Andreghetto FM, Moulatlet AC, da Silva VE, de Castro MG, Nunes FD, Brandao LG, Severino P. MiR-9 and miR-21 as prognostic biomarkers for recurrence in papillary thyroid cancer. Clin Exp Metastasis. 2015;32:521-30.

2. Hundahl SA, Fleming ID, Fremgen AM, Menck HR. A National Cancer Data Base report on 53,856 cases of thyroid carcinoma treated in the U.S., 1985-1995. Cancer. 1998;83:2638-48.

3. Cooper DS, Doherty GM, Haugen BR, Kloos RT, Lee SL, Mandel SJ, Mazzaferri EL, Mclver B, Sherman SI, Tuttle RM, American Thyroid Association Guidelines T. Management guidelines for patients with thyroid nodules and differentiated thyroid cancer. Thyroid. 2006;16:109-42.

4. Pellegriti G, Scollo C, Lumera G, Regalbuto C, Vigneri R, Belfiore A. Clinical behavior and outcome of papillary thyroid cancers smaller than $1.5 \mathrm{~cm}$ in diameter: study of 299 cases. J Clin Endocrinol Metab. 2004;89:3713-20.

5. Grant CS. Recurrence of papillary thyroid cancer after optimized surgery. Gland Surg. 2015;4:52-62.

6. Eszlinger $M$, Paschke R. Molecular fine-needle aspiration biopsy diagnosis of thyroid nodules by tumor specific mutations and gene expression patterns. Mol Cell Endocrinol. 2010;322:29-37.

7. American Thyroid Association Guidelines Taskforce on Thyroid N, Differentiated Thyroid C, Cooper DS, Doherty GM, Haugen BR, Kloos RT, Lee SL, Mandel SJ, Mazzaferri EL, Mclver B, et al. Revised American Thyroid Association management guidelines for patients with thyroid nodules and differentiated thyroid cancer. Thyroid. 2009;19:1167-214.

8. Cady B, Rossi R. An expanded view of risk-group definition in differentiated thyroid carcinoma. Surgery. 1988;104:947-53.

9. Prasad NB, Somervell H, Tufano RP, Dackiw AP, Marohn MR, Califano JA, Wang Y, Westra WH, Clark DP, Umbricht CB, et al. Identification of genes differentially expressed in benign versus malignant thyroid tumors. Clin Cancer Res. 2008:14:3327-37.

10. Calin GA, Dumitru CD, Shimizu M, Bichi R, Zupo S, Noch E, Aldler H, Rattan $\mathrm{S}$, Keating $\mathrm{M}$, Rai $\mathrm{K}$, et al. Frequent deletions and down-regulation of microRNA genes miR15 and miR16 at 13q14 in chronic lymphocytic leukemia. Proc Natl Acad Sci U S A. 2002;99:15524-9.

11. Ma L, Teruya-Feldstein J, Weinberg RA. Tumour invasion and metastasis initiated by microRNA-10b in breast cancer. Nature. 2007:449:682-8.

12. Bryant RJ, Pawlowski T, Catto JW, Marsden G, Vessella RL, Rhees B, Kuslich C, Visakorpi T, Hamdy FC. Changes in circulating microRNA levels associated with prostate cancer. Br J Cancer. 2012;106:768-74.

13. Brase JC, Wuttig D, Kuner R, Sultmann H. Serum microRNAs as non-invasive biomarkers for cancer. Mol Cancer. 2010;9:306.

14. Pallante $P$, Visone $R$, Ferracin $M$, Ferraro A, Berlingieri MT, Troncone G, Chiappetta G, Liu CG, Santoro M, Negrini M, et al. MicroRNA deregulation in human thyroid papillary carcinomas. Endocr Relat Cancer. 2006;13:497-508.

15. Nikiforova MN, Tseng GC, Steward D, Diorio D, Nikiforov YE. MicroRNA expression profiling of thyroid tumors: biological significance and diagnostic utility. J Clin Endocrinol Metab. 2008;93:1600-8.

16. Chen YT, Kitabayashi N, Zhou XK, Fahey 3rd TJ, Scognamiglio T. MicroRNA analysis as a potential diagnostic tool for papillary thyroid carcinoma. Mod Pathol. 2008;21:1139-46.

17. Tetzlaff MT, Liu A, Xu X, Master SR, Baldwin DA, Tobias JW, Livolsi VA, Baloch ZW. Differential expression of miRNAs in papillary thyroid carcinoma compared to multinodular goiter using formalin fixed paraffin embedded tissues. Endocr Pathol. 2007:18:163-73.

18. He H, Jazdzewski K, Li W, Liyanarachchi S, Nagy R, Volinia S, Calin GA, Liu CG, Franssila K, Suster $S$, et al. The role of microRNA genes in papillary thyroid carcinoma. Proc Natl Acad Sci U S A. 2005;102:19075-80.

19. Lee JC, Zhao JT, Clifton-Bligh RJ, Gill A, Gundara JS, Ip JC, Glover A, Sywak MS, Delbridge LW, Robinson BG, Sidhu SB. MicroRNA-222 and microRNA-146b are tissue and circulating biomarkers of recurrent papillary thyroid cancer. Cancer. 2013;119:4358-65.
20. Shaha AR, Shah JP, Loree TR. Patterns of failure in differentiated carcinoma of the thyroid based on risk groups. Head Neck. 1998:20:26-30.

21. Wittekind C. Lymph nodes, tumour deposits, and TNM: are we getting better? 7th edition of UICC 2010 TNM classification of malignant tumors. Strahlenther Onkol. 2012;188:191-2.

22. Livak KJ, Schmittgen TD. Analysis of relative gene expression data using real-time quantitative PCR and the 2(-delta delta $C(T))$ method. Methods. 2001;25:402-8.

23. Wang Q, Chu B, Zhu J, Zhang S, Liu Y, Zhuang M, Yang Y. Clinical analysis of prophylactic central neck dissection for papillary thyroid carcinoma. Clin Transl Oncol. 2014:16:44-8.

24. Lee YS, Kim SW, Kim SW, Kim SK, Kang HS, Lee ES, Chung KW. Extent of routine central lymph node dissection with small papillary thyroid carcinoma. World J Surg. 2007;31:1954-9.

25. Machens $\mathrm{A}$, Holzhausen $\mathrm{HJ}$, Dralle $\mathrm{H}$. The prognostic value of primary tumor size in papillary and follicular thyroid carcinoma. Cancer. 2005;103:2269-73.

26. Suh YJ, Kwon H, Kim SJ, Choi JY, Lee KE, Park YJ, Park do J, Youn YK. Factors affecting the locoregional recurrence of conventional papillary thyroid carcinoma after surgery: a retrospective analysis of 3381 patients. Ann Surg Oncol. 2015:22:3543-9.

27. Roh JL, Kim JM, Park Cl. Central lymph node metastasis of unilateral papillary thyroid carcinoma: patterns and factors predictive of noda metastasis, morbidity, and recurrence. Ann Surg Oncol. 2011;18:2245-50.

28. Chou CK, Chen RF, Chou FF, Chang HW, Chen YJ, Lee YF, Yang KD, Cheng JT, Huang CC, Liu RT. miR-146b is highly expressed in adult papillary thyroid carcinomas with high risk features including extrathyroidal invasion and the BRAF(V600E) mutation. Thyroid. 2010;20:489-94.

29. Visone R, Russo L, Pallante P, De Martino I, Ferraro A, Leone V, Borbone E, Petrocca F, Alder H, Croce CM, Fusco A. MicroRNAs (miR)-221 and miR-222, both overexpressed in human thyroid papillary carcinomas, regulate p27Kip1 protein levels and cell cycle. Endocr Relat Cancer. 2007;14:791-8.

30. Sheu SY, Grabellus F, Schwertheim S, Worm K, Broecker-Preuss M, Schmid KW. Differential miRNA expression profiles in variants of papillary thyroid carcinoma and encapsulated follicular thyroid tumours. Br J Cancer. 2010;102:376-82.

31. Yang Z, Zhang Y, Zhang X, Zhang M, Liu H, Zhang S, Qi B, Sun X. Serum microRNA-221 functions as a potential diagnostic and prognostic marker for patients with osteosarcoma. Biomed Pharmacother. 2015;75:153-8.

32. Vergho DC, Kneitz S, Kalogirou C, Burger M, Krebs M, Rosenwald A, Spahn M, Loser A, Kocot A, Riedmiller H, Kneitz B. Impact of miR-21, miR-126 and miR-221 as prognostic factors of clear cell renal cell carcinoma with tumor thrombus of the inferior vena cava. PLoS One. 2014;9:e109877.

33. Mazeh H, Mizrahi I, Halle D, llyayev N, Stojadinovic A, Trink B, MitraniRosenbaum S, Roistacher M, Ariel I, Eid A, et al. Development of a microRNA-based molecular assay for the detection of papillary thyroid carcinoma in aspiration biopsy samples. Thyroid. 2011;21:111-8.

34. Mattia G, Errico MC, Felicetti F, Petrini M, Bottero L, Tomasello L, Romania P, Boe A, Segnalini P, Di Virgilio A, et al. Constitutive activation of the ETS-1-miR-222 circuitry in metastatic melanoma. Pigment Cell Melanoma Res. 2011;24:953-65.

35. Pan Y, Li J, Zhang Y, Wang N, Liang H, Liu Y, Zhang CY, Zen K, Gu H. Slug-upregulated miR-221 promotes breast cancer progression through suppressing E-cadherin expression. Sci Rep. 2016;6:25798.

36. Coarfa C, Fiskus W, Eedunuri VK, Rajapakshe K, Foley C, Chew SA, Shah SS, Geng C, Shou J, Mohamed JS, et al. Comprehensive proteomic profiling identifies the androgen receptor axis and other signaling pathways as targets of microRNAs suppressed in metastatic prostate cancer. Oncogene. 2016;35:2345-56. 